\title{
Clinical prediction rules combining signs, symptoms and epidemiological context to distinguish influenza from influenza-like illnesses in primary care: a cross sectional study
}

Barbara Michiels ${ }^{1 *}$, Isabelle Thomas ${ }^{2}$, Paul Van Royen ${ }^{1}$, Samuel Coenen ${ }^{1,3}$

\begin{abstract}
Background: During an influenza epidemic prompt diagnosis of influenza is important. This diagnosis however is still essentially based on the interpretation of symptoms and signs by general practitioners. No single symptom is specific enough to be useful in differentiating influenza from other respiratory infections. Our objective is to formulate prediction rules for the diagnosis of influenza with the best diagnostic performance, combining symptoms, signs and context among patients with influenza-like illness.

Methods: During five consecutive winter periods (2002-2007) 138 sentinel general practitioners sampled (nasoand oropharyngeal swabs) 4597 patients with an influenza-like illness (ILI) and registered their symptoms and signs, general characteristics and contextual information. The samples were analysed by a DirectigenFlu-A\&B and RT-PCR tests. 4584 records were useful for further analysis.

Starting from the most relevant variables in a Generalized Estimating Equations (GEE) model, we calculated the area under the Receiver Operating Characteristic curve (ROC AUC), sensitivity, specificity and likelihood ratios for positive (LR+) and negative test results (LR-) of single and combined signs, symptoms and context taking into account pre-test and post-test odds.

Results: In total 52.6\% (2409/4584) of the samples were positive for influenza virus: 64\% (2066/3212) during and $25 \%$ (343/1372) pre/post an influenza epidemic. During and pre/post an influenza epidemic the LR+ of 'previous flu-like contacts', 'coughing', 'expectoration on the first day of illness' and 'body temperature above $37.8^{\circ} \mathrm{C}$ ' is $3.35(95 \% \mathrm{Cl} 2.67-4.03)$ and $1.34(95 \% \mathrm{Cl} 0.97-1.72)$, respectively. During and pre/post an influenza epidemic the LR- of 'coughing' and 'a body temperature above $37.8^{\circ} \mathrm{C}$ ' is $0.34(95 \% \mathrm{Cl} 0.27-0.41)$ and $0.07(95 \% \mathrm{Cl} 0.05-0.08)$, respectively.

Conclusions: Ruling out influenza using clinical and contextual information is easier than ruling it in. Outside an influenza epidemic the absence of cough and fever $\left(>37,8^{\circ} \mathrm{C}\right)$ makes influenza 14 times less likely in ILI patients. During an epidemic the presence of 'previous flu-like contacts', cough, 'expectoration on the first day of illness' and fever $\left(>37,8^{\circ} \mathrm{C}\right)$ increases the likelihood for influenza threefold. The additional diagnostic value of rapid point of care tests especially for confirming influenza still has to be established.
\end{abstract}

\footnotetext{
* Correspondence: barbara.michiels@ua.ac.be

'Department of Primary and Interdisciplinary Care (Centre for General Practice), University of Antwerp, Universiteitsplein 1, B-2610 Antwerp,

Belgium

Full list of author information is available at the end of the article
}

\section{Biomed Central}

(c) 2011 Michiels et al; licensee BioMed Central Ltd. This is an Open Access article distributed under the terms of the Creative Commons Attribution License (http://creativecommons.org/licenses/by/2.0), which permits unrestricted use, distribution, and reproduction in any medium, provided the original work is properly cited. 


\section{Background}

Especially during an influenza pandemic prompt diagnosis of influenza is important for the individual patient and society as well. Diagnosing of influenza is still essentially based on the interpretation of symptoms and signs, notwithstanding the growing support of point-ofcare tests.

All primary care practitioners and especially members of influenza surveillance systems (Fluview(Ilinet), USA: http://www.cdc.gov/flu/, Euroflu, Europe: http://www. euroflu.org) need a performing prediction rule to diagnose influenza. The clinical definitions used for reporting cases of influenza in different surveillance systems [1-3] vary widely, are often imprecise and have never been evaluated [4]. Most frequently inclusion criteria for influenza-like illness (ILI) are based on four to six of the nine criteria (sudden onset, cough, rigors and chills, fever, prostration and weakness, headache, myalgia, widespread aches and pain, influenza in close contact) of the ICHPPC-2 classification (International Classification of Health Problems in Primary Care)[5]. A poor relation between these criteria and laboratory confirmed influenza cases has been reported[6,7].

It is important to distinguish between the classic influenza syndrome consisting of sudden onset, fever, headache, cough, sore throat, myalgia, nasal congestion, weakness and loss of appetite[8], and those symptoms and signs which can be used to discriminate from other ILIs. Besides recurrent symptoms like cough and fever, there are other symptoms like acute onset[8,9], malaise, chills, sore throat, muscle pain and nose symptoms $[10,11]$, that were found in one study, but could not be confirmed in another. Unfortunately these symptoms are frequently seen in other respiratory infections caused by a variety of viral and non-viral pathogens. No single symptom is specific enough to be useful in differentiating influenza from these respiratory infections[10].

Since the development of clinical prediction rules systematically combining symptoms and other information might be a more useful strategy[11], the goal of this study is to formulate a prediction rule for influenza in patients presenting with an ILI with the best diagnostic performance in general practice based on the combination of symptoms, signs and contextual information.

\section{Methods}

\section{Setting, design and participants}

A large cross sectional study was conducted based on the information collected during five consecutive surveillance periods (2002-2007) by the sentinel network of general practitioners (GPs) commissioned by the Scientific Institute of Public Health (SIPH), Brussels in Belgium http:// www.iph.fgov.be/epidemio/epien/index10.htm. Age, gender and geographic distribution of the participating GPs are representative for Belgium. Eligible patients were informed about the goal of influenza surveillance, no written informed consent was provided. The information was handled totally anonymously. Ethics approval was granted. Each surveillance period, i.e. from October (week 40) until April (week 20), the sentinel GPs took one oro- and two naso-pharyngeal swabs from some of their patients (all ages) consulting with a new ILI characterized by a broad clinical picture with sudden onset of fever (measurement and threshold undefined), respiratory symptoms (like cough) and systemic symptoms (like myalgia). At the same time they registered the corresponding symptoms and signs as well as general characteristics and contextual information by checking each item if positive on a pre-printed form. Only swab sampled records were included in this study. The swabs were stored in a transport medium (Eagle's minimum essential medium, with addition of antibiotics and antimycotics) before sending them by post (free of charge) to the laboratory of virology of the SIPH National Influenza Centre.

\section{Test methods}

The swabs were tested upon reception using a rapid antigen diagnostic test (DirectigenFlu_A\&B). The samples were then submitted to a panel of RT-PCR assays (real time or nested polymerase chain reaction) for typing Influenza A and B, our reference test. All influenza A positive samples were then sub typed ( $\mathrm{H} 1 \mathrm{~N} 1$ and H3N2). Laboratory personal was blinded for the clinical information.

The index tests consisted of a combination of some of the following symptoms or signs collected on the pre-printed form: sudden onset, shivering, weakness, headache, muscle pain, lack of appetite, cough, expectoration, nose-, eye- and ear symptoms, red throat, dyspnoea, rhonchi, gastro-intestinal symptoms, confusion, dizziness, age (years), the number of illness days (from the start of the first ILI symptoms to the day swabs were taken), influenza vaccination, ILI contacts in the family, school- or workplace, highest body temperature $\left({ }^{\circ} \mathrm{C}\right)$ measured before the intake of antipyretics.

\section{Data management}

In the original data file body temperature was dichotomized to below (or equal to) and above $37.8^{\circ} \mathrm{C}$. The number of illness days exceeding 14 days were considered as missing.

Extra variables were introduced: 'influenza year', corresponding to the surveillance period each year, starting in October; 'influenza epidemic' corresponding to whether or not the number of ILI consultations exceeds the 
threshold of 100 cases per 100000 inhabitants (Source: European Influenza Surveillance Scheme for Belgium [12]); 'RSV (Respiratory Syncytial Virus) epidemic', corresponding to whether or not more than 100 confirmed RSV cases per week were reported by the sentinel laboratories in Belgium[13]. No RSV testing was performed on the swabs.

\section{Statistical methods}

Positively skewed variables were log transformed. The pattern of missing data was considered to be at random (MAR). The variables with missing values (temperature, age and number of illness days) were included in an imputation model with all other symptom variables, influenza epidemic and RSV epidemic. Besides the main effects the interactions were also present in the imputation model, ensuring that interactions could properly be allowed in the analysis models. We conducted $10 \mathrm{impu-}$ tations using the MCMC (Markov chain Monte Carlo) method (= a single chain for all imputations with 200 burn-in iterations followed by 100 iterations between successive imputations) stratified for the five influenza years, using the multiple imputation procedure of SAS (version 9.2).

Each imputed data set was analysed using a GEE (Generalized Estimating Equations) model with influenza positive PCR as the dependent variable and GP code as a cluster variable (as a check on possible clustering of inclusion criteria and symptom registration within GPs). A backward regression analysis starting from a model with all symptoms and interaction terms (pre-planned on clinical relevance) between all symptoms and influenza epidemic, RSV epidemic, vaccine use, number of illness days and age was performed. When convergence problems occurred the responsible variable was eliminated. After stepwise elimination of interaction terms a forward introduction of interaction terms with borderline $\mathrm{p}$-value was executed. The final model contained all single symptoms, signs and contextual variables together with interaction terms with a p-value less than 0.001 (to deal with multiple comparisons). Parameter estimates of relevant variables and interaction terms were then averaged across data sets by using a bootstrap technique (SAS macro)[14].

Starting from the most relevant variables in the GEE model, we calculated the area under the Receiver Operating Characteristic (ROC) curve (AUC), sensitivity, specificity and likelihood ratios for positive $(\mathrm{LR}+)$ and negative test results (LR-) for different single signs, symptoms and context and their combinations taking into account pre-test and post-test odds as described by Janssens A et al[15].

To enforce the internal validity, the outcomes and their 95\% confidence interval (CI) were calculated using a bootstrap method. The combination of symptoms, signs and/or context with the best LR+ and LR- were used to define clinical prediction rules taking into account logical clinical order. Finally, sensitivity analyses were done for the different influenza strains A and B, for the different surveillance periods, for different age categories and on the records with complete data.

\section{Results}

In total 138 sentinel general practitioners included and sampled 4597 of all eligible ILI patients (exact number unknown) during the 5 surveillance periods (Table 1Figure 1). Information about the general characteristics of the eligible non-participants and reasons for non-participation were not registered. Most records (25.22\%) were collected in year 2006-2007. Thirteen records missed data for all signs and symptoms, $18.7 \%$ records missed one or more data (maximum three per record; temperature $=14 \%$, age $=2 \%$, illness days $=5 \%$ ) Through imputing missing data 4584 records could be analysed. No relevant differences were seen between the original, the complete record and the imputed database. In this last database the mean age was 30 (SE 0.28), the mean number of illness days was 1.8 (SE 0.02) and the mean number of positive symptoms was 8.6 (SE 0.04), and $10 \%$ were vaccinated against influenza. $70 \%$ (3212/ 4584 ) of the records were collected during an influenza epidemic and 44\% (2036/4584) during an RSV epidemic.

$52.6 \%$ of the swabs were found positive for influenza on RT-PCR, which corresponds to a pre-test odds of 1.11 (adjusted by bootstrapping to 1.01 (95\%CI 0.941.08)). The final GEE model contained all the variables recorded and defined except confusion. It was eliminated because of convergence problems. Only two interaction terms were withheld: influenza epidemic" ILI contacts and expectoration*illness days.

During an influenza epidemic 64\% (2066/3212) of the records were positive for influenza compared with $25 \%$ $(343 / 1372)$ before or after (Figure 2). Besides influenza epidemic other important predictors of influenza cases were no vaccination, body temperature above $37.8^{\circ} \mathrm{C}$, cough, nose symptoms and expectoration on the first day of illness (Table 2). ILI contacts were more predictive pre/post an epidemic (ORadj 3.14 (2.23-4.05)) than during an epidemic (ORadj 1.24 (1.03-1.44)). Age and many symptoms such as sudden onset, shivering, weakness, headache, muscle pain, lack of appetite and eye symptoms were also no longer significant in the adjusted full model. There was no difference between the two groups for ear symptoms, red throat, dyspnoea, rhonchi, gastro-intestinal problems, confusion and dizziness.

The variables influenza epidemic, ILI contacts, cough, expectoration, body temperature $>37.8^{\circ} \mathrm{C}$ and the 
Table 1 General characteristics of the included subjects

\begin{tabular}{|c|c|c|c|}
\hline & $\begin{array}{c}\text { All subjects } \\
(n=4597)\end{array}$ & $\begin{array}{l}\text { Subjects with } \\
\text { full records } \\
(\mathrm{n}=3738)\end{array}$ & $\begin{array}{l}\text { Subjects with full and } \\
\text { imputed records } \\
(\mathrm{n}=4584)\end{array}$ \\
\hline Patient age & $(n=4510)$ & & \\
\hline Median (range) & 28 (0 to 99$)$ & 27 (0 to 99$)$ & $28(0$ to 99$)$ \\
\hline Mean (SE) & $30.0(0.29)$ & $29.4(0.32)$ & $30.0(0.28)$ \\
\hline \multicolumn{4}{|l|}{ Number of subjects (\%) } \\
\hline \multicolumn{4}{|l|}{ By influenza year } \\
\hline $2002-2003$ & $585(12.73)$ & $479(12.81)$ & $584(12.74)$ \\
\hline 2003-2004 & $1066(23.19)$ & $851(22.77)$ & $1064(23.21)$ \\
\hline $2004-2005$ & $996(21.67)$ & $825(22.07)$ & $995(21.71)$ \\
\hline $2005-2006$ & $785(17.08)$ & $663(17.74)$ & $785(17.12)$ \\
\hline 2006-2007 & $1165(25.34)$ & $920(24.61)$ & $1156(25.22)$ \\
\hline During an influenza epidemic & $3221(70.07)$ & $2650(70.89)$ & $3212(70.07)$ \\
\hline With ILI-contact in family. school- or workplace & $1492(32.46)$ & $1195(31.97)$ & $1490(32.50)$ \\
\hline Vaccinated against influenza & $466(10.14)$ & $377(10.09)$ & $465(10.14)$ \\
\hline During an RSV epidemic & $2039(44.36)$ & $1635(43.74)$ & $2036(44.42)$ \\
\hline \multicolumn{4}{|l|}{ Number of symptoms } \\
\hline Median (range) & $8(0$ to 18$)$ & $9(1$ to 18$)$ & 9 (1 to 18$)$ \\
\hline Mean (SE) & $8.4(0.04)$ & $8.6(0.04)$ & $8.6(0.04)$ \\
\hline Number of illness days ${ }^{a}$ & $(n=4381)$ & & \\
\hline Median (range) & 1.5 (0 to 39$)$ & $1.5(0$ to 14$)$ & $2(0$ to 14$)$ \\
\hline Mean (SE) & $1.76(0.02)$ & $1.72(0.02)$ & $1.77(0.02)$ \\
\hline Number of records per GP & $(n=138)$ & $(n=134)$ & $(n=137)$ \\
\hline Median (range) & 10 (1 to 247$)$ & 7 (1 to 217 ) & 10 (1 to 246$)$ \\
\hline Mean (SE) & $33.5(4.5)$ & $27.9(4.0)$ & $33.5(4.5)$ \\
\hline
\end{tabular}

$\mathrm{SE}=$ standard error.

aillness days above 14 days were considered as missing.

interaction terms 'ILI contacts'"epidemic and expectoration"'number of illness days' all had a p-value $<0,0001$ in the multivariate model. Influenza epidemic, ILI contacts, cough, 'expectoration per illness day', nose symptoms, lack of appetite and 'body temperature $>37.8^{\circ} \mathrm{C}$ ' are the most performing symptoms to discriminate influenza from other ILIs according the AUROC (Table 3). Starting with influenza epidemic and stepwise adding ILI contacts, cough, body temperature and expectoration per day (prediction rule 1 ) or adding cough and body temperature (prediction rule 2) both give a final AUC of 0.75 (0.73-0.76). Adding more variables does not raise the AUC any further.

During an influenza epidemic variables with high sensitivity such as cough $(0.82(0.81-0.84))$ and body temperature $(0.91(0.89-0.92))$ have a poor specificity (respectively 0.39 (0.36-0.42) and 0.19 (0.16-0.22)) (Table 4). During the pre/post epidemic period specific variables such as ILI contact $(0.82(0.80-0.85))$, 'expectoration on the first day' $(0.92(0.65-1.00)$ have a bad corresponding sensitivity $(0.42(0.36-0.47)$ and 0.11 (0.00-0.42), respectively).

In general the LR- of the different symptoms performs better than the LR+. The values are alike during and pre/post an influenza epidemic, except for ILI contacts because of the significant interaction of this variable with influenza epidemic.

The LR+ of an influenza epidemic is 1.50 (1.43-1.57). Prediction rule 1 then gives a cumulative $L R+$ of 3.35 (2.67-4.03) and an LR- of 0.26 (0.18-0.34). Prediction rule 2 gives a cumulative $\mathrm{LR}+$ of $2.26(2.11-2.40)$ and an LR- of 0.34 (0.27-0.41). Adding more information has no additional diagnostic value.

The LR- of an influenza epidemic is 0.30 (0.26-0.33). In this situation 'previous ILI contacts' is more important and this information raises the likelihood by a factor of 2.36. For prediction rule 1 the cumulative LR+ now is $1.34(0.97-1.72)$. The corresponding LR- is 0.04 (0.03-0.05). For prediction rule 2 the $L R+$ now is 0.46 (0.41-0.51), the LR- is $0.07(0.05-0.08)$. When some symptoms are present and others are absent the prediction rules have lower LR+ and higher LR-.

There is no statistical or relevant difference in performance of both prediction rules between influenza $A$ and $\mathrm{B}$, nor between the surveillance periods or ages (Table 5). Pre/post an influenza epidemic no prediction rule can help to confirm influenza in the age group $<5$ years and $>65$ years. Ruling out influenza seems to be easier in the younger age groups. 


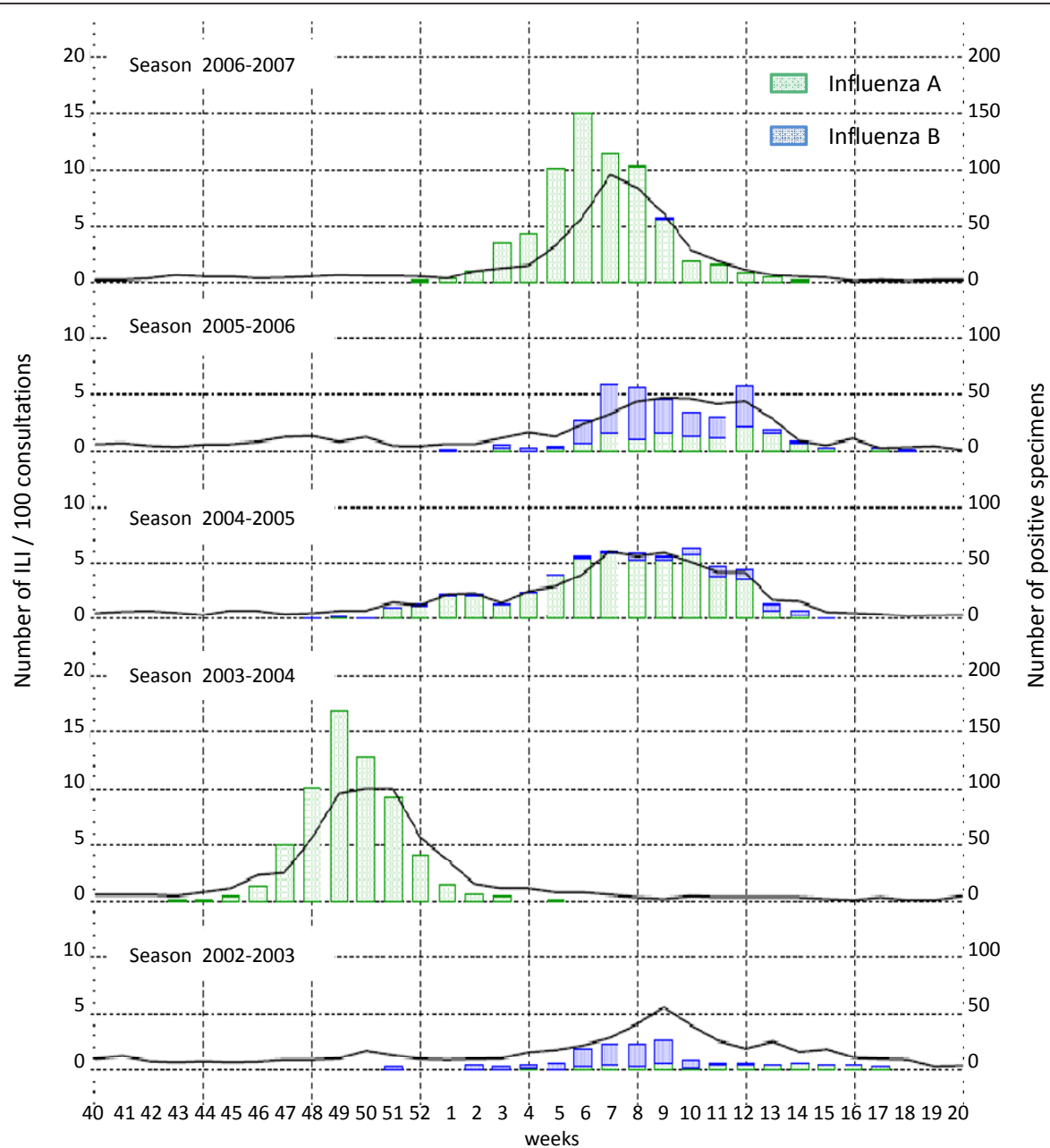

Figure 1 Number of influenza-like illness (ILI) per 100 consultations and number of influenza positive specimens season 2002/2003 to season 2006/2007. Note: this figure is part of the historical graphs made by the National Influenza Centre, Virology, Brussels, Belgium http://www.euroflu.org/html/hist_graphs.html and used here with their permission.

\section{Discussion}

In patients presenting with ILI in primary care ruling out influenza is easier than confirming it. Pre/post an influenza epidemic the absence of cough and fever $\left(>37.8^{\circ} \mathrm{C}\right)$ lowers a pre-test probability of $25 \%$ to a posttest probability of $7 \%$. During an epidemic with a pretest probability of $62 \%$, the absence of these symptoms gives a post-test probability of $27 \%$. To confirm influenza the presence of previous ILI contacts', cough, 'expectoration on the first illness day' combined with 'fever $>37.8^{\circ} \mathrm{C}$ ' results in a post-test probability of $79 \%$. Pre/post an epidemic the presence of these items gives a post-test probability of $60 \%$.

Our study had to deal with some limitations. Our study was not designed to evaluate the additional value of rapid point of care tests, which were only performed in the virology laboratory and not at the GP practice.

Only $20,7 \%$ of the records mentioned expectoration on the first day of illness. Normally influenza is defined as a respiratory infection with a dry cough. So this symptom was only helpful in a minority of cases in the confirmation of influenza, but even when absent prediction rule 1 is still quite useful with a LR+ of 2.38 during an influenza epidemic.

Gender information is missing in our study, but until now no difference has been described between males and females in the symptomatology of influenza.

Sentinel GPs did not include every patient with ILI. The choices they made and the reasons for them are unclear: sometimes the number of swabs were restricted by the virology lab and patients could refuse to participate. There is no reason to believe that a systematic selection bias took place. Especially patients with higher fever are included by the sentinel GPs and this must be kept in mind, when extrapolating our results. The youngest age group ( $<5$ years) is under-represented in our database. Probably because it is not easy to take swabs from small children and/or in Belgium parents could have chosen to go 


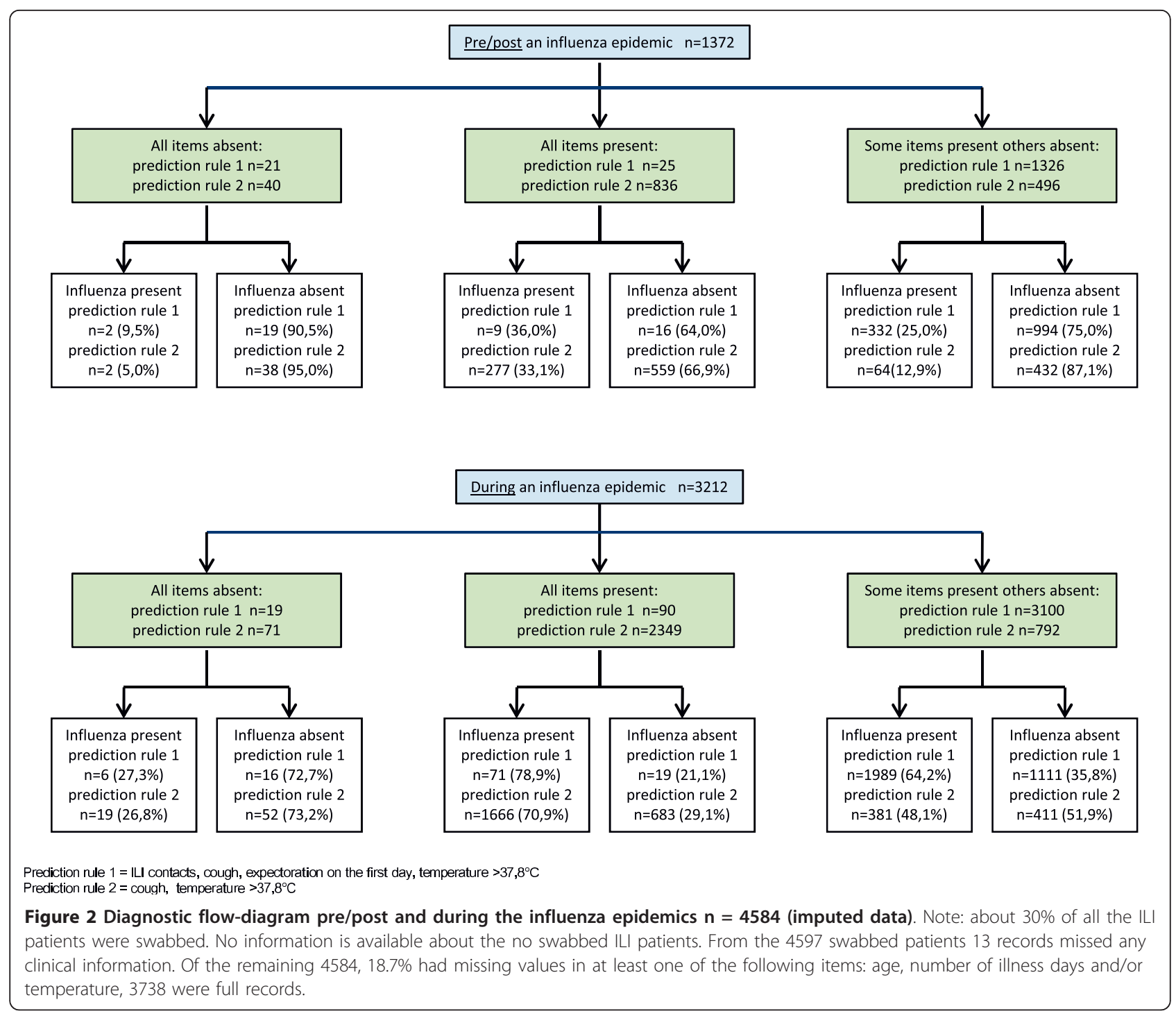

directly to a paediatrician for their first consult. Especially in this age group extra validation is required. There are a smaller amount of samples in the older ( $>64$ years) age group, but this is merely due to the lower incidence of influenza in this age group.

The advantage of our study is the large number of records over five surveillance periods. This allows an extensive analysis and robust results. An advanced statistical approach was adopted to deal with missing data other than the outcome variable to correct for potential biases or overestimation of diagnostic values and multiple comparisons. We also took into account the influence of symptoms, signs or context already considered on the diagnostic values of new items added as well as interactions.

That expectoration is only important when occurring during the first few days has never been considered in other studies [Additional file 1]. Carrat et al[4] found expectoration to be present more frequently among influenza A positive patients. Loda[16], describing the symptoms of volunteers with an influenza illness after nasal inoculation by a wild type influenza $\mathrm{A}$, found that cough, rhonchi and expiratory fine rales were the most frequent and persistent manifestations. Of the initial 426 cases of the 2009 pandemic influenza A (H1N1) cases $104(24.5 \%)$ suffered from sputum production on admission in hospital[17]. This percentage is comparable with the incidence of expectoration on the first day of illness in influenza cases in our study (25.3\%).

The number of illness days up to now has never been tested in interaction with other variables and was seldom considered as a continuous variable. Stein et al[18] compared the performance of clinician judgement, a rapid influenza test and the prediction rule cough and 
Table 2 Presence of context, signs and symptoms in influenza positive and negative subjects and corresponding crude $^{a}$ and adjusted odds ratios $(95 \% \mathrm{Cl})^{b}$

\begin{tabular}{|c|c|c|c|c|}
\hline Contexts. signs and symptoms & $\begin{array}{l}\text { Influenza pos } \\
(n=2409)\end{array}$ & $\begin{array}{l}\text { Influenza neg } \\
(n=2175)\end{array}$ & $\begin{array}{c}\text { Crude OR } \\
(95 \% \mathrm{Cl})\end{array}$ & $\begin{array}{c}\text { Adjusted OR } \\
(95 \% \mathrm{Cl})\end{array}$ \\
\hline Body temperature $>37.8^{\circ} \mathrm{C}$. No. (\%) & $2271(94.3)$ & $1902(87.5)$ & $2.36(1.91$ to 2.92$)$ & $2.13(1.58 \text { to } 2.68)^{c}$ \\
\hline Sudden onset. No. (\%) & $2154(89.4)$ & $1874(86.2)$ & 1.36 (1.14 to 1.62$)$ & 1.25 (0.99 to 1.51$)$ \\
\hline Influenza epidemic. No. (\%) & $2066(85.8)$ & $1146(52.7)$ & 5.41 (4.69 to 6.23$)$ & $6.28(5.03 \text { to } 7.54)^{c}$ \\
\hline Cough. No. (\%) & $2060(85.5)$ & $1425(65.5)$ & $3.11(2.69$ to 3.59$)$ & $2.59(2.14 \text { to } 3.04)^{c}$ \\
\hline Shivering. No. (\%) & $1999(83.0)$ & $1706(78.4)$ & $1.34(1.16$ to 1.55$)$ & $1.13(0.92$ to 1.33$)$ \\
\hline Weakness. No. (\%) & $1965(81.6)$ & $1691(77.7)$ & $1.27(1.10$ to 1.46$)$ & 1.03 (0.84 to 1.21$)$ \\
\hline Headache. No. (\%) & $1918(79.6)$ & $1590(73.1)$ & $1.44(1.25$ to 1.65$)$ & 1.16 (0.96 to 1.37$)$ \\
\hline Muscle pain. No. (\%) & $1838(76.3)$ & $1567(72.0)$ & 1.25 (1.09 to 1.43$)$ & $1.16(0.97$ to 1.36$)$ \\
\hline Nose symptoms. No. (\%) & $1620(67.2)$ & $1208(55.5)$ & $1.64(1.46$ to 1.85$)$ & 1.38 (1.18 to 1.58$)$ \\
\hline Red throat. No. (\%) & $1529(63.5)$ & $1333(61.3)$ & $1.10(0.97$ to 1.24$)$ & 0.95 (0.81 to 1.09) \\
\hline Lack of appetite. No. (\%) & $1453(60.3)$ & $1130(52.0)$ & $1.41(1.25$ to 1.58$)$ & 1.15 (0.98 to 1.32$)$ \\
\hline RSV epidemic. No. (\%) & $1026(42.6)$ & $1010(46.4)$ & $0.86(0.76$ to 0.96$)$ & $1.14(0.99$ to 1.29$)$ \\
\hline ILI contacts in the family. school or workplace. No. (\%) & $928(38.5)$ & $562(25.8)$ & $1.80(1.59$ to 2.04$)$ & Not in model \\
\hline ILI contacts pre/post an epidemic. No. (\%). $n=1372$ & $134(39.1)$ & $180(17.5)$ & $3.02(2.31$ to 3.96$)$ & $3.14(2.23 \text { to } 4.05)^{c}$ \\
\hline ILI contacts during an epidemic. No. $(\%)^{c} . n=3212$ & $79^{\prime} 4(38.4)$ & $382(33.3)$ & $1.25(1.07$ to 1.45$)$ & $1.24(1.03$ to 1.44$)$ \\
\hline Expectoration. No. (\%) & $661(27.4)$ & $456(21.0)$ & $1.43(1.24$ to 1.63$)$ & Not in model \\
\hline Expectoration on illness day 0. No. (\%). $n=117$ & $9(18.37)$ & $15(22.06)$ & 0.80 (0.32 to 2.00$)$ & $2.24(0.93$ to 3.55$)$ \\
\hline Expectoration on illness day 1. No. (\%). $n=2101$ & $269(25.33)$ & $165(15.88)$ & $1.80(1.45$ to 2.23$)$ & $1.36(1.06 \text { to } 1.66)^{c}$ \\
\hline Expectoration on illness day 2. No. (\%). n = 1676 & $262(27.61)$ & $159(21.87)$ & 1.35 (1.09 to 1.71$)$ & $1.00(0.83$ to 1.17$)$ \\
\hline Eye symptoms. No. (\%) & $659(27.4)$ & $481(22.1)$ & $1.33(1.16$ to 1.52$)$ & 1.08 (0.90 to 1.27$)$ \\
\hline Gastro-intestinal symptoms. No. (\%) & $368(15.3)$ & $374(17.2)$ & $0.87(0.74$ to 1.02$)$ & $0.84(0.68$ to 1.00$)$ \\
\hline Ear symptoms. No. (\%) & $355(14.7)$ & $304(14.0)$ & $1.06(0.90$ to 1.26$)$ & 0.88 (0.71 to 1.05$)$ \\
\hline Dyspnoe. No. (\%) & $236(9.8)$ & $186(8.6)$ & $1.16(0.95$ to 1.42$)$ & 1.18 (0.90 to 1.45$)$ \\
\hline Dizziness. No. (\%) & $233(9.7)$ & $177(8.1)$ & $1.21(0.99$ to 1.48$)$ & 1.18 (0.87 to 1.48$)$ \\
\hline Vaccination against influenza. No. (\%) & $198(8.2)$ & $267(12.3)$ & $0.64(0.53$ to 0.78$)$ & 0.67 (0.50 to 0.85$)$ \\
\hline Ronchi. No. (\%) & $166(6.9)$ & $136(6.3)$ & $1.11(0.88$ to 1.40$)$ & $0.93(0.65$ to 1.20$)$ \\
\hline Confusion. No. (\%) & $22(0.9)$ & $22(1.0)$ & $0.90(0.50$ to 1.63$)$ & not in model \\
\hline Age difference of 10 years & NA & NA & NA & 0.97 (0.94 to 1.01$)$ \\
\hline Age. mean $(S E)^{c}$ & $28.90(0.39)$ & $31.27(0.41)$ & NA & Not in model \\
\hline Temp. mean $(S E)^{c}$ & $38.70(0.01)$ & $38.46(0.02)$ & NA & Not in model \\
\hline
\end{tabular}

$\mathrm{NA}=$ not applicable $\mathrm{Cl}=$ confidence interval.

${ }^{\text {a }}$ Crude Odds ratios were estimated using $\mathrm{Chi}^{2}$.

${ }^{\mathrm{b}}$ Adjusted odds ratios were estimated using Generalized Estimating Equations. $95 \% \mathrm{Cl}$ were calculated by bootstrap after multiple imputation.

'significant different: $\mathrm{p}$-value $<0.0001$.

fever, and did not see a significant effect of the duration of illness on the overall accuracy of the latter prediction rule. This is confirmed by our findings. In addition, the diagnostic value of symptoms and signs outside epidemics is scarce in the literature. To date, the value of information about previous contact with other ILI cases, especially pre/post the epidemic, has never been shown. The prevailing prediction rule has been generated from a selected patient population that was recruited to study the effects of neuraminidase inhibitors. The strict inclusion criteria for those studies excluded many patients that would have normally presented for evaluation of acute respiratory symptoms in primary care[18].

During an influenza epidemic our findings about cough and fever especially, corroborate previous findings. Boivin et al concluded in 2000 that the combination of cough, fever and the knowledge of an epidemic gave the best prediction and that physicians could correctly diagnose influenza in over $60-70 \%$ of their patients on the basis of clinical symptoms alone[19]. The systematic review of Call et al[10], including the large study of Monto[8], showed that no symptom or sign had an LR+ greater than 2 in studies that enrolled patients with disregard to age. To rule out influenza the absence of fever (LR- 0.40; 95\%CI: 0.25-0.66), cough (LR- 0.42; 0.31-0.57) or nasal congestion (LR- $0.49 ; 0.42-0.59$ ) were the only findings that had an LR- less than 0.5 .

In our study we found small, not statistically significant, differences in diagnostic accuracy of the two prediction rules according to different age-categories, and no 
Table 3 Area under the Receiver Operating Characteristic curve $(95 \% \mathrm{Cl})$ of symptoms, signs and context, single or in combination, for the diagnosis of influenza

\begin{tabular}{|c|c|c|c|c|c|c|c|}
\hline \multirow{2}{*}{$\begin{array}{l}\text { Symptoms. signs and context } \\
\text { Influenza epidemic }\end{array}$} & \multirow{2}{*}{$\frac{\text { Single }}{\mathbf{0 . 6 7}(0.65 \text { to } 0.68)}$} & \multicolumn{6}{|c|}{ Combinations } \\
\hline & & Influenza epidemic + & Influenza epidemic + & Influenza epidemic + & Influenza epidemic + & Influenza epidemic + & Influenza epidemic + \\
\hline ILI contacts & 0.56 (0.55 to 0.58$)$ & 0.68 (0.67 to 0.70$)$ & ILI contacts $^{\mathrm{a}}+$ & ILI contacts + & ILI contacts + & $0.72(0.71-0.74)$ & $0.74(0.72-0.75)$ \\
\hline Cough & 0.60 (0.59 to 0.61$)$ & $\mathbf{0 . 7 1}$ (0.70 to 0.72 ) & $\mathbf{0 . 7 2}$ (0.71 to 0.74$)$ & Cough + & Cough + & Cough+ & Cough+ \\
\hline Temp $>37.8^{\circ} \mathrm{C}$ & 0.54 (0.53 to 0.55$)$ & 0.69 (0.68 to 0.70$)$ & 0.71 (0.69 to 0.72 ) & $\mathbf{0 . 7 4}$ (0.72 to 0.75 ) & Temp $>37.8^{\circ} \mathrm{C}+$ & $0.75(0.73-0.76)$ & Temp+ \\
\hline Expectoration*illness day ${ }^{b}$ & $0.56(0.55$ to 0.58$)$ & 0.70 (0.68 to 0.71$)$ & 0.70 (0.69 to 0.72 ) & $0.73(0.72$ to 0.75$)$ & $\mathbf{0 . 7 5}(0.73$ to 0.76$)$ & 0.72 (0.71 to 0.74$)$ & $\mathbf{0 . 7 5}(0.73$ to 0.76$)$ \\
\hline Lack of appetite & 0.54 (0.53 to 0.56$)$ & 0.69 (0.67 to 0.70$)$ & 0.70 (0.68 to 0.71$)$ & $0.73(0.72$ to 0.74$)$ & 0.74 (0.73 to 0.76$)$ & $0.72(0.71$ to 0.74$)$ & 0.75 (0.73 to 0.76$)$ \\
\hline Nose symptoms & $0.56(0.54$ to 0.57$)$ & 0.69 (0.68 to 0.71$)$ & 0.70 (0.69 to 0.72 ) & 0.73 (0.71 to 0.74$)$ & 0.74 (0.73 to 0.76$)$ & 0.70 (0.69 to 0.72 ) & 0.75 (0.74 to 0.76$)$ \\
\hline Expectoration & $0.53(0.52$ to 0.54$)$ & 0.68 (0.67 to 0.69$)$ & 0.69 (0.68 to 0.71$)$ & 0.72 (0.71 to 0.74$)$ & 0.74 (0.72 to 0.75$)$ & 0.71 (0.70 to 0.73$)$ & 0.75 (0.73 to 0.76$)$ \\
\hline Muscle pain & 0.52 (0.51 to 0.53$)$ & 0.68 (0.66 to 0.69 ) & 0.69 (0.68 to 0.71$)$ & 0.73 (0.71 to 0.74$)$ & 0.74 (0.73 to 0.76$)$ & 0.72 (0.70 to 0.73$)$ & 0.75 (0.73 to 0.76$)$ \\
\hline Flu 'vaccine & 0.52 (0.51 to 0.53$)$ & 0.67 (0.66 to 0.69$)$ & 0.69 (0.67 to 0.70$)$ & 0.73 (0.71 to 0.74$)$ & 0.74 (0.72 to 0.75$)$ & 0.72 (0.70 to 0.73$)$ & 0.75 (0.73 to 0.76$)$ \\
\hline Vertigo & 0.51 (0.50 to 0.52$)$ & 0.67 (0.66 to 0.68 ) & 0.69 (0.67 to 0.70$)$ & 0.73 (0.71 to 0.74 ) & 0.74 (0.73 to 0.75$)$ & 0.71 (0.70 to 0.73 ) & 0.75 (0.73 to 0.76 ) \\
\hline
\end{tabular}


Table 4 The sensitivity, specificity, likelihood ratios of the positive (LR+) and negative test result (LR-) of single and combined symptoms, signs and context for the diagnosis of influenza $(95 \% \mathrm{CI})^{a}$

\begin{tabular}{|c|c|c|c|c|c|c|}
\hline Symptoms. signs and context & $\begin{array}{c}\text { Sensitivity } \\
(95 \% \mathrm{Cl})\end{array}$ & $\begin{array}{c}\text { Specificity } \\
(95 \% \mathrm{Cl})\end{array}$ & $\begin{array}{c}\text { LR+ } \\
(95 \% \mathrm{Cl})\end{array}$ & $\begin{array}{c}\text { Cumulative }^{\mathbf{b}} \\
\text { LR+ } \\
(95 \% \mathrm{Cl})\end{array}$ & $\begin{array}{c}\text { LR- } \\
(95 \% \mathrm{Cl})\end{array}$ & $\begin{array}{c}\text { Cumulative }^{b} \\
\text { LR- } \\
(95 \% \mathrm{Cl})\end{array}$ \\
\hline Influenza epidemic & 0.88 (0.86 to 0.89$)$ & 0.42 (0.39 to 0.44$)$ & 1.50 (1.43 to 1.57$)$ & & 0.30 (0.26 to 0.33$)$ & \\
\hline During an epidemic & & & 1.50 (1.43 to 1.57$)$ & & 1.50 (1.43 to 1.57$)$ & \\
\hline \multicolumn{7}{|l|}{ Prediction rule 1} \\
\hline +ILI contact & 0.42 (0.38 to 0.46$)$ & 0.63 (0.58 to 0.68 ) & $1.12(1.01$ to 1.24$)$ & 1.68 (1.49 to 1.88$)$ & 0.93 (0.87 to 0.98$)$ & 1.38 (1.28 to 1.49$)$ \\
\hline+ cough & 0.81 (0.79 to 0.84 ) & 0.40 (0.36 to 0.44$)$ & 1.35 (1.29 to 1.40$)$ & 2.27 (2.01 to 2.53$)$ & 0.47 (0.42 to 0.52$)$ & 0.65 (0.56 to 0.74$)$ \\
\hline +expectoration day 1 & 0.10 (0.00 to 0.40$)$ & 0.93 (0.67 to 1.00$)$ & $1.30(1.08$ to 1.53$)$ & 2.96 (2.38 to 3.54$)$ & $0.93(0.86$ to 1.00$)$ & 0.54 (0.40 to 0.68$)$ \\
\hline +body temp $>37.8^{\circ} \mathrm{C}$ & 0.90 (0.87 to 0.92$)$ & 0.21 (0.16 to 0.26$)$ & 1.13 (1.08 to 1.19$)$ & 3.35 (2.67 to 4.03$)$ & 0.49 (0.41 to 0.58$)$ & 0.26 (0.18 to 0.34$)$ \\
\hline \multicolumn{7}{|l|}{ Prediction rule 2} \\
\hline+ cough & 0.82 (0.81 to 0.84$)$ & 0.39 (0.36 to 0.42 ) & 1.34 (1.29 to 1.39$)$ & 2.01 (1.90 to 2.13$)$ & $0.46(0.41$ to 0.51$)$ & 0.69 (0.60 to 0.78$)$ \\
\hline +body temp $>37.8^{\circ} \mathrm{C}$ & 0.91 (0.89 to 0.92 ) & 0.19 (0.16 to 0.22$)$ & $1.12(1.08$ to 1.16$)$ & 2.26 (2.11 to 2.40$)$ & 0.49 (0.40 to 0.58$)$ & 0.34 (0.27 to 0.41$)$ \\
\hline Pre/post an epidemic & & & 0.30 (0.26 to 0.33$)$ & & 0.30 (0.26 to 0.33$)$ & \\
\hline \multicolumn{7}{|l|}{ Prediction rule 1} \\
\hline + ILI contact & 0.42 (0.36 to 0.47$)$ & 0.82 (0.80 to 0.85 ) & 2.36 (1.93 to 2.79$)$ & 0.69 (0.54 to 0.85$)$ & 0.71 (0.64 to 0.78) & 0.21 (0.18 to 0.24$)$ \\
\hline+ cough & 0.81 (0.78 to 0.85$)$ & 0.40 (0.34 to 0.46$)$ & 1.35 (1.28 to 1.42$)$ & 0.93 (0.73 to 1.14$)$ & 0.47 (0.41 to 0.53 ) & 0.11 (0.09 to 0.13 ) \\
\hline +expectoration day 1 & 0.11 (0.00 to 0.42 ) & 0.92 (0.65 to 1.00$)$ & 1.30 (1.08 to 1.53$)$ & 1.21 (0.89 to 1.54$)$ & 0.93 (0.85 to 1.00$)$ & 0.09 (0.06 to 0.11$)$ \\
\hline +body temp $>37.8^{\circ} \mathrm{C}$ & 0.92 (0.88 to 0.95$)$ & 0.17 (0.11 to 0.23 ) & 1.11 (1.05 to 1.16$)$ & 1.34 (0.97 to 1.72$)$ & 0.48 (0.39 to 0.57$)$ & 0.04 (0.03 to 0.05$)$ \\
\hline \multicolumn{7}{|l|}{ Prediction rule 2} \\
\hline+ cough & 0.78 (0.76 to 0.81 ) & 0.45 (0.42 to 0.48 ) & $1.42(1.37$ to 1.47$)$ & 0.42 (0.38 to 0.47$)$ & 0.49 (0.43 to 0.54$)$ & $0.14(0.12$ to 0.17$)$ \\
\hline +body temp $>37.8^{\circ} \mathrm{C}$ & $0.93(0.91$ to 0.95$)$ & 0.15 (0.12 to 0.17$)$ & 1.09 (1.06 to 1.12$)$ & $0.46(0.41$ to 0.51$)$ & 0.48 (0.39 to 0.57$)$ & 0.07 (0.05 to 0.08$)$ \\
\hline
\end{tabular}

$\mathrm{Cl}=$ confidence interval.

${ }^{a}$ analysis was performed on the database with full and imputed records $n=4584$.

${ }^{\mathrm{b}}$ cumulative $=$ combined diagnostic value of all the symptoms. signs or context taken into account so far.

statistically significant interaction between the individual variables and age in the multivariate model. In the study of Carrat[4], with a smaller sample size, this was also the case. Govaerts et al[9] concluded that fever and cough (and acute onset) give the best prediction in a population of $60+$ elderly during an influenza season (without preselection). The different symptom patterns for different strains, found by Carrat[4], could not be confirmed by Monto $[8,10]$. We found a significantly different $L R+$ for cough and fever between influenza A and B, but the clinical significance of this finding is limited.

The derivation and part of the validation $[20,21]$ have been achieved for prediction rule 1. Prediction rule 2 has previously been mentioned in the literature $[18,19]$ and is now broadly validated in our study. A large prospective diagnostic study for influenza taking into account our remarks might generate the broad validation and impact analysis necessary to successfully implement our findings.

\section{Conclusions}

In patients presenting with an influenza-like illness to primary care, the asymmetric diagnostic values of combinations of clinical and contextual information, i.e. ruling out is easier than ruling in, have important implications for the management of influenza. Outside an epidemic, influenza is easily ruled out by the absence of cough and fever. Clinical and contextual information alone might not be sufficient to rule in influenza and to make treatment decisions, although 'expectoration on the first day of illness' combined with 'previous flu-like contacts', cough and fever $\left(>37,8^{\circ} \mathrm{C}\right)$ increases the likelihood of influenza threefold during an epidemic. The place and the additional diagnostic value of rapid point of care tests on top of clinical and contextual information still has to be established.

\section{Additional material}

Additional file 1: literature compilation regarding influenza diagnosis. Additional file with information about previous published prediction rules and diagnostic accuracy studies.

\section{Acknowledgements}

We thank Fernande Yane, predecessor of IT who initiated the study and was responsible for the start of the data collection. We also thank the general practitioners of the Belgian Sentinel Network for the gathering of the data. The data collection by the Belgian Sentinel Network, was funded by the Flemish and French Ministry of Welfare, Public Health and Family. The analysis was funded by the Department of Primary and Interdisciplinary Care (Centre for General Practice), University of Antwerp, Antwerp, Belgium. The sponsor of the study had no role in study design; in the collection, analysis, and interpretation of data; in the writing of the manuscript; and in the decision to submit the manuscript for publication. 
Table 5 Likelihood ratios of the positive (LR+) and negative test result (LR-) of two prediction rules ${ }^{\mathrm{a}}$ in subgroups of the imputed original database and in the full record database $(95 \% \mathrm{Cl})$

\begin{tabular}{|c|c|c|c|c|c|c|}
\hline & \multirow[b]{2}{*}{ Prediction rule $^{a}$} & \multirow[b]{2}{*}{$\mathbf{n}$} & \multicolumn{2}{|c|}{ During influenza epidemic } & \multicolumn{2}{|c|}{ Pre/post an influenza epidemic } \\
\hline & & & $\mathrm{LR}+$ & LR- & LR+ & LR- \\
\hline \multirow[t]{2}{*}{ Full record analysis } & 1 & 3738 & 3.65 (1.76 to 5.54$)$ & 0.23 (0.08 to 0.37$)$ & 1.23 (0.34 to 2.11) & 0.04 (0.01 to 0.06$)$ \\
\hline & 2 & & 2.24 (1.95 to 2.54$)$ & $0.27(0.12$ to 0.41$)$ & 0.43 (0.33 to 0.54$)$ & 0.05 (0.02 to 0.08$)$ \\
\hline \multirow[t]{2}{*}{ Influenza A } & 1 & 4176 & 3.43 (2.69 to 4.18 ) & 0.30 (0.20 to 0.40$)$ & 1.46 (1.05 to 1.87$)$ & 0.05 (0.03 to 0.06 \\
\hline & 2 & & 2.21 (2.06 to 2.36$)$ & $0.33(0.26$ to 0.41$)$ & $0.46(0.40$ to 0.51$)$ & 0.07 (0.05 to 0.09$)$ \\
\hline \multirow[t]{2}{*}{ Influenza B } & 1 & 2566 & 5.05 (3.75 to 6.36$)$ & 0.13 (0.07 to 0.19$)$ & 1.16 (0.64 to 1.68$)$ & 0.01 (0.00 to 0.02 ) \\
\hline & 2 & & 4.01 (3.68 to 4.33 ) & 0.34 (0.20 to 0.48$)$ & 0.49 (0.37 to 0.61$)$ & 0.04 (0.02 to 0.07$)$ \\
\hline \multirow[t]{2}{*}{ Influenza year (2002 - 2003) } & 1 & 584 & 3.73 (0.63 to 6.83) & 0.13 (0.00 to 0.32 ) & 1.79 (0.19 to 3.39$)$ & 0.06 (0.00 to 0.13$)$ \\
\hline & 2 & & 2.28 (1.72 to 2.83$)$ & $0.22(0.00$ to 0.45$)$ & 1.08 (0.84 to 1.32$)$ & 0.10 (0.01 to 0.19$)$ \\
\hline \multirow[t]{2}{*}{ Influenza year (2003 - 2004) } & 1 & 1064 & $4.00(0.49$ to 7.51$)$ & $0.13(0.04$ to 0.21$)$ & $1.72(0.00$ to 4.10$)$ & 0.02 (0.01 to 0.03$)$ \\
\hline & 2 & & 2.19 (1.87 to 2.51$)$ & 0.25 (0.15 to 0.36$)$ & $0.36(0.24$ to 0.47$)$ & 0.04 (0.02 to 0.06$)$ \\
\hline \multirow[t]{2}{*}{ Influenza year (2004 - 2005) } & 1 & 995 & 3.93 (2.07 to 5.78) & $0.32(0.13$ to 0.51$)$ & 3.03 (1.64 to 4.42$)$ & 0.07 (0.03 to 0.10$)$ \\
\hline & 2 & & 2.52 (2.16 to 2.88$)$ & 0.42 (0.23 to 0.62$)$ & 0.79 (0.65 to 0.93$)$ & 0.13 (0.07 to 0.19$)$ \\
\hline \multirow[t]{2}{*}{ Influenza year (2005 - 2006) } & 1 & 785 & 2.90 (1.03 to 4.77$)$ & 0.40 (0.05 to 0.74$)$ & 0.65 (0.28 to 1.02$)$ & $0.06(0.02$ to 0.11$)$ \\
\hline & 2 & & 2.90 (2.47 to 3.33$)$ & 0.61 (0.29 to 0.92) & $0.50(0.40$ to 0.60$)$ & 0.10 (0.06 to 0.15$)$ \\
\hline \multirow[t]{2}{*}{ Influenza year (2006 - 2007) } & 1 & 1156 & 2.04 (1.19 to 2.90$)$ & 0.33 (0.09 to 0.57 ) & 1.07 (0.39 to 1.75$)$ & 0.04 (0.01 to 0.08$)$ \\
\hline & 2 & & 1.79 (1.59 to 2.00$)$ & 0.24 (0.13 to 0.35$)$ & $0.38(0.27$ to 0.50$)$ & 0.05 (0.02 to 0.08$)$ \\
\hline \multirow[t]{2}{*}{ Age $<5$ years } & 1 & 267 & 2.70 (0.00 to 6.02) & 0.06 (0.00 to 0.82) & 0.69 (0.00 to 2.24$)$ & 0.01 (0.00 to 0.11$)$ \\
\hline & 2 & & 1.58 (1.10 to 2.05$)$ & 0.12 (0.00 to 1.12$)$ & 0.25 (0.08 to 0.42$)$ & $0.02(0.00$ to 0.17$)$ \\
\hline \multirow[t]{2}{*}{ Age 5 to 14 years } & 1 & 931 & 3.57 (1.08 to 6.07$)$ & $0.14(0.00$ to 0.27$)$ & $1.43(0.25$ to 2.61$)$ & 0.03 (0.00 to 0.05$)$ \\
\hline & 2 & & 1.91 (1.65 to 2.16$)$ & $0.22(0.02$ to 0.42$)$ & $0.44(0.32$ to 0.56$)$ & 0.05 (0.00 to 0.10$)$ \\
\hline \multirow[t]{2}{*}{ Age 15 to 64 years } & 1 & 3137 & 3.77 (2.69 to 4.85) & $0.31(0.22$ to 0.41$)$ & 1.71 (1.09 to 2.34 ) & 0.05 (0.03 to 0.07 ) \\
\hline & 2 & & 2.29 (2.10 to 2.48$)$ & 0.32 (0.24 to 0.41$)$ & 0.48 (0.42 to 0.54$)$ & 0.07 (0.05 to 0.09$)$ \\
\hline \multirow[t]{2}{*}{ Age $>64$ years } & 1 & 249 & 5.31 (0.00 to 20.43) & 0.39 (0.00 to 1.01$)$ & 0.67 (0.00 to 2.91) & 0.14 (0.00 to 0.29$)$ \\
\hline & 2 & & 1.68 (0.91 to 2.44$)$ & 0.24 (0.00 to 0.73$)$ & $0.46(0.26$ to 0.66$)$ & 0.07 (0.00 to 0.16$)$ \\
\hline
\end{tabular}

$\mathrm{Cl}=$ confidence interval.

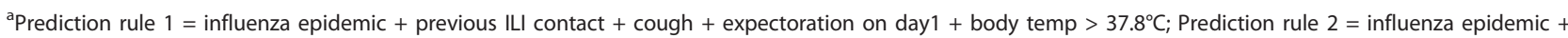
cough + body temp $>37.8^{\circ} \mathrm{C}$.

\section{Author details}

${ }^{1}$ Department of Primary and Interdisciplinary Care (Centre for General Practice), University of Antwerp, Universiteitsplein 1, B-2610 Antwerp, Belgium. ${ }^{2}$ Scientific Institute of Public Health, National Influenza Centre, Virology, Juliette Wytsmanstraat 14, B-1050 Brussels, Belgium. ${ }^{3}$ Laboratory of Medical Microbiology, Vaccine \& Infectious Disease Institute (VAXINFECTIO), University of Antwerp, Universiteitsplein 1, B-2610 Antwerp, Belgium.

\section{Authors' contributions}

BM initiated and designed the study, obtained funding, was involved in analyzing and interpreting the data and in writing the manuscript. IT was responsible for data collection and was involved in revising the manuscript. SC and PVR were involved in analyzing and interpreting data and in revising the manuscript. All authors had full access to all of the data (including statistical reports and tables) in the study and can take responsibility for the integrity of the data and the accuracy of the data analysis and have seen and approved the final manuscript.

\section{Competing interests}

The authors declare that they have no competing interests.

Received: 30 November 2010 Accepted: 9 February 2011 Published: 9 February 2011

\section{References}

1. Centres for Disease Control and Prevention: Prevention and Control of Influenza. Recommendations of the Advisory Committee on Immunization Practices (ACIP). MMWR Recomm Rep 2008, 57(RR-7):1-59.
2. Thomas I, Yane F, Gérard C, Libotte ML, Bontinck L, Brochier B: Surveillance van Griep in België. Seizoen 2007 - 2008, jaarrapport. [Surveillance of Influenza in Belgium. Season 2007-2008, annual report]. Brussels: National Influenza Centre; 2009.

3. Meerhoff TJ, Meijer A, Paget WJ: Methods for sentinel virological surveillance of influenza in Europe - an 18-country survey. Euro Surveill 2004, 9(1):442.

4. Carrat F, Tachet A, Rouzioux C, Housset B, Valleron AJ: Evaluation of clinical case definitions of influenza: detailed investigation of patients during the 1995-1996 epidemic in France. Clin Infect Dis 1999, 28(2):283-290.

5. Classification Committee of WONCA (World Organization of National Colleges A and Academic Associations of General Practitioners/Family Physicians): Inclusion criteria for the use of the rubrics of the International Classification of Health Problems in Primary Care. New York: Oxford University Press; 1983487.

6. Navarro-Marí JM, Pérez-Ruiz M, Cantudo-Muñoz P, Petit-Gancedo C, Jiménez-Valera M, Rosa-Fraile M, Influenza Surveillance Network in Andalusia S: Influenza-like illness criteria were poorly related to laboratory confirmed influenza in a sentinel surveillance study. J Clin Epidemiol 2005, 58(3):275-279.

7. van Elden $L$, van Essen GA, Boucher CA, van Loon AM, Nijhuis M, Schipper P, Verheij TJ, Hoepelman IM: Clinical diagnosis of influenza virus infection: evaluation of diagnostic tools in general practice. $\mathrm{Br} J \mathrm{Gen}$ Pract 2001, 51:630-634.

8. Monto AS, Gravenstein S, Elliott M, Colopy M, Schweinle J: Clinical signs and symptoms predicting influenza infection. Arch Intern Med 2000, 160:3243-3247.

9. Govaert TM, Dinant GJ, Aretz K, Knottnerus JA: The predictive value of influenza symptomatology in elderly people. Fam Pract 1998, 15:16-22. 
10. Call SA, Vollenweider MA, Hornung CA, Simel DL, McKinney WP: Does this patient have influenza? JAMA 2005, 293(8):987-997.

11. Ebell $M H$, White $L L$, Casault $T$ : A systematic review of the history and physical examination to diagnose influenza. J Am Board Fam Pract 2004 17(1):1-5.

12. Influenza Historic Graphs. [http://www.euroflu.org/html/hist_graphs.html].

13. [Peillaboratoria: Respiratoir Syncytiaal Virus] Sentinel laboratoria: respiratory syncytial virus. [http://iph.fgov.be/epidemio/epinl/plabnl/ plabannl/07_085n_v.pdf]

14. Barker N: A Practical Introduction to the Bootstrap Using the SAS System. SAS Conference Proceedings: Phuse 2005: October 10-12 2005: Heidelberg, Germany SAS 2005, pk02.

15. Janssens AC, Deng Y, Borsboom G, Eijkemans M, Habbema JD, Steyerberg E: A new logistic regression approach for the evaluation of diagnostic test results. Med Decis Making 2005, 25:168-177.

16. Knight $V$ : New research on influenza: studies with normal volunteers. Ann Int Med 1965, 62(6):1307-1325.

17. Cao B, Li XW, Mao Y, Wang J, Lu HZ, Chen YS, Liang ZA, Liang L, Zhang SJ, Zhang B, et al: Clinical features of the initial cases of 2009 pandemic influenza A (H1N1) virus infection in China. N Engl J Med 2009, 361(26):2507-2517.

18. Stein J, Louie J, Flanders S, Maselli J, Hacker JK, Drew WL, Gonzales R: Performance characteristics of clinical diagnosis, a clinical decision rule, and a rapid influenza test in the detection of influenza infection in a community sample of adults. Ann Emerg Med 2005, 46(5):412-419.

19. Boivin G, Hardy I, Tellier G, Maziade J: Predicting influenza infections during epidemics with use of a clinical case definition. Clin Infect Dis 2000, 31(5):1166-1169.

20. Falk G, Fahey T: Clinical prediction rules. Diagnosis in General Practice. BMJ 2009, 339(b2899).

21. McGinn TG, Guyatt GH, Wyer PC, Naylor CD, Stiell IG, Richardson WS: Users' guides to the medical literature: XXII: how to use articles about clinical decision rules. Evidence-Based Medicine Working Group. JAMA 2000, 284(1):79-84.

\section{Pre-publication history}

The pre-publication history for this paper can be accessed here: http://www.biomedcentral.com/1471-2296/12/4/prepub

doi:10.1186/1471-2296-12-4

Cite this article as: Michiels et al: Clinical prediction rules combining signs, symptoms and epidemiological context to distinguish influenza from influenza-like illnesses in primary care: a cross sectional study. BMC Family Practice 2011 12:4.

\section{Submit your next manuscript to BioMed Central and take full advantage of:}

- Convenient online submission

- Thorough peer review

- No space constraints or color figure charges

- Immediate publication on acceptance

- Inclusion in PubMed, CAS, Scopus and Google Scholar

- Research which is freely available for redistribution

Submit your manuscript at www.biomedcentral.com/submit 